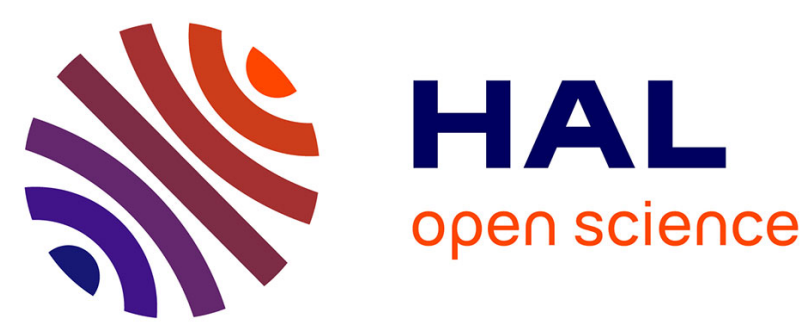

\title{
Deformation structures in the frontal prism near the Japan Trench: Insights from sandbox models
}

Santanu Bose, Puspendu Saha, James J Mori, Christie Rowe, Kohtaro Ujiie, Frederick M Chester, Marianne Conin, Christine Regalla, Jun Kameda, Virginia Toy, et al.

\section{To cite this version:}

Santanu Bose, Puspendu Saha, James J Mori, Christie Rowe, Kohtaro Ujiie, et al.. Deformation structures in the frontal prism near the Japan Trench: Insights from sandbox models. Journal of Geodynamics, 2015, 89, pp.29 - 38. 10.1016/j.jog.2015.06.002 . hal-02457738

\section{HAL Id: hal-02457738 \\ https://hal.univ-lorraine.fr/hal-02457738}

Submitted on 28 Jan 2020

HAL is a multi-disciplinary open access archive for the deposit and dissemination of scientific research documents, whether they are published or not. The documents may come from teaching and research institutions in France or abroad, or from public or private research centers.
L'archive ouverte pluridisciplinaire HAL, est destinée au dépôt et à la diffusion de documents scientifiques de niveau recherche, publiés ou non, émanant des établissements d'enseignement et de recherche français ou étrangers, des laboratoires publics ou privés. 
Deformation structures in the frontal prism near the Japan Trench: insight from Sandbox Models

4

${ }^{1}$ University of Calcutta, Department of Geology, Experimental Tectonic Laboratory, 35 Ballygunge Circular Road, Kolkata-700 019 India

${ }^{2}$ Earthquake Hazards Division, Disaster Prevention Research Institute, Kyoto University Gokasho, Uji Kyoto 611-0011 Japan

${ }^{3}$ Earth and Planetary Sciences Department, McGill University, 3450 University Street, Montreal, QC H3A 0E8 Canada

${ }^{4}$ Graduate School of Life and Environmental Sciences, University of Tsukuba, 1-1-1

Tennodai,Tsukuba 305-0006 Japan

${ }^{5}$ Center for Tectonophysics, Department of Geology and Geophysics, Texas A\&M University, College Station TX 77843-3115 USA

${ }^{6}$ EA4098 LaRGE, Université des Antilles et de la Guyane, Pointe-à-Pitre, France.

${ }^{7}$ Department of Geosciences, The Pennsylvania State University, University Park PA 16802 USA

${ }^{8}$ Department of Natural History Sciences, Faculty of Science, Hokkaido University, Sapporo 060-0810, Japan

${ }^{9}$ Department of Geology, University of Otago, 360 Leith Walk, Dunedin 9054 New Zealand

${ }^{10}$ Department of Geosciences, Colorado State University, Fort Collins, Colorado, USA

${ }^{11}$ Dipartimento di Scienzedella Terra, Università di Modena e Reggio Emilia largo, S. Eufemia, 1941100 Modena Italy

${ }^{12}$ Department of Earth and Planetary Sciences, University of California Santa Cruz, 1156 High, St., Santa Cruz, CA 95064 USA

${ }^{13}$ Center for Coastal and Ocean Mapping, Joint Hydrographic Center, University of New Hampshire, 24 Colovos Road, Durham NH 03824 USA

${ }^{14}$ Institute for Research on Earth Evolution, JAMSTEC, Yokohama, Japan

${ }^{15}$ Department of Earth Sciences,Indian Institute of Technology, Roorkee- 247667, Uttarakhand India

*Correspondence to: bose.santanu@gmail.com

\section{Abstract}

We have used sandbox experiments to explore the mechanics of the frontal prism structures documented by new borehole and seismic reflection data from IODP Expedition 343 (JFAST). This study investigated the effects of down-dip (across 
trench axis) variations in frictional resistance along a decollement on the structural development of frontal wedges near subduction zones. To clarify our understanding on the wedge growth over horst-and-graben structures in the subducting plate near the Japan Trench, we performed sandbox experiments with alternate zone of relatively

51 high and low friction on the basal decollement. Our experiments verify that high

52 frictional resistance on the basal fault is needed to produce the observed internal deformation and fault-and-fold structures in the core samples collected during JFAST.

54 Varying down-dip frictional resistance along the decollement causes a temporal change in the style of internal deformation within the wedge and often gives rise to two distinctive structural domains, separated by a break in the surface slope of the wedge: (i) complexly deformed inner wedge with steep surface slope and (ii) shallow taper outer wedge, characterized by a sequence of imbricate thrusts. Our experiments further demonstrate that the topographic slope-break in the wedge develops when the hinterland part of the wedge essentially stops deforming internally, leading to insequence thrusting with the formation of outer wedge with low taper angle. For a series of alternate high and low frictional conditions on the basal fault the slope of the wedge varies temporally between topographic slope-break and uniformly sloping 64 wedge.

Keywords: sandbox experiments, inner and outer wedge, slope-break, horst-andgraben structure, fault friction

67

\section{Introduction}

It is now well known that the subduction of bathymetric features in the oceanic

70 plate, e.g., seamounts, aseismic ridges, volcanic plateaus has a strong influence on the

71 development of diverse morphological features and deformation structures in the 
overriding plate (Domingues et al., 2000; Malavieille, 1984; von Huene and Culotta, 1989; von Huene and Lallemand, 1990; Lallemand et al., 1992; Lallemand et al., 1994; von Huene et al., 2004; Park et al., 1999; Wang and Hu, 2006). However, their studies indicate that the styles of deformation in the overriding plate vary with the geometry of bathymetric features in the subducting plate. For example, the subduction of seamounts develops steeper surface slope in the inner wedge than that in the outer wedge (Park et al., 1999; Domingues et al., 2000). On the contrary, the subduction of aseismic ridges develops steep outer wedge slope associated with almost flat inner wedge (Lallemand et al., 1992). Despite dominance of horst-and-graben structure at most trenches, its influence on frontal wedge growth has still remained relatively unexplored. We therefore focus the present work to analyze the impacts of subducted horst-and-graben structures on the evolution of frontal wedge near the Japan Trench. Geophysical investigations along several sections across the Japan Trench (Fig. 1b and c) recorded a series of horst-and-graben structures on the subducting plate beneath the frontal wedge (Tsuru et al., 2002; Kodaira et al., 2012; Nakamura et al., 2013). Moreover, earlier studies have shown that the sediment thickness in the incoming Pacific plate near the Japan Trench is thin and the thinning of sediment cover mostly occurs above the horst block (Groshong, 2006). The combination of the effects of the differences in sediment thickness and surface roughness over horst-andgraben structure in the subducting plate cause varying degrees of coupling at the plate interface, creating varying frictional properties on the decollement (Pacheco et al., 1993; Tanioka et al., 1997; von Huene et al., 1999; Bilek, 2007; Das and Watts, 2009). In the present study we have used sandbox experiments to simulate the effects of down-dip variations in the frictional strength on the basal decollement to investigate the structural development of frontal wedge and finally, provide a 
mechanical model for explaining the structural evolution of frontal wedge over horst and graben structure near the Japan Trench.

Integrated Ocean Drilling Program (IODP) Expedition 343 (JFAST) drilled to a depth of 836 meters below seafloor (mbsf) near the Japan Trench at site C0019 through the plate boundary fault zone over the horst block, located about $\sim 6 \mathrm{~km}$ westward from the trench axis (Fig. 1a). Core samples collected during the expedition have provided a great opportunity to compare our experimental results with the observed deformation structures within the frontal wedge (Chester et al., 2013, Kirkpatrick et al., 2014). Borehole data and associated seismic images provide new structural information that has been modeled in this study to show the effects of friction on the megathrust near the Japan Trench.

\section{Experimental methods and materials}

Sandbox experiments have proved to be useful in understanding the mechanics of thin-skinned accretionary wedges using the concept of critical taper theory (Chapple, 1978; Boyer and Elliot, 1982; Davis et al., 1983; Dahlen, 1990). The angle of critical taper is defined by the summation of basal inclination $(\beta)$ and surface slope $(\alpha)$. According to critical taper model, a wedge deforms internally and thereby, increases its taper and at a critically tapered angle the wedge develops internal stresses, leading the wedge on the verge of failure. At this stage, shear stress at the base reaches a value that assists frictional sliding at the decollement (Davis, 1983; Boyer and Elliot, 1982). Theoretically and experimentally it has been shown that the angle of critical taper is proportional to the frictional condition on the basal decollement according to the following equation (Dahlen, 1990): 


$$
\alpha+\beta=\left(\beta+\mu_{b}\right)\left(\frac{1-\sin \phi_{c}}{1+\sin \phi_{c}}\right)
$$

where, $\mu_{b}$ is the coefficient of static friction on the decollement and $\phi_{c}$ is the angle of internal friction of the frontal prism material. In the present study, we have prepared our experimental models over varying

126 down-dip frictional conditions on the decollement to simulate the effect of horst-and127 graben structure along the basal decollement (Fig.2). We have considered relatively 128 higher frictional coefficient on the decollement above the horst block because of its 129 enhanced surface irregularities due to little or no sediment cover, leading to a strong 130 coupling with the overriding plate than that over the graben sediments. Thus the horst 131 and graben structure gives rise to alternate zones of relatively strong and a weak 132 contact respectively with the overriding plate on the decollement. In the laboratory 133 scaled experiments the higher basal friction $\left(\mu_{b}=0.46\right)$, simulating the decollement 134 immediately above the horst block, was achieved by pasting commercial sand paper 135 (P30, average grit size 622.0 microns) on a glass plate and a relatively lower basal 136 friction $\left(\mu_{b}=0.36\right)$ was obtained by sieving a veneer of boric acid powder $(0.001 \mathrm{~mm}$ 137 beads) over the glass plate in order to model the frictional strength above the graben 138 sediments. However, in some experiments we pasted rigid block of $5 \mathrm{~mm}$ thick acrylic 139 sheet over the basal glass plate to model the horst block. However, in the second set 140 of experiments, we had to stop the experiment once the buttress reached the edge of 141 the acrylic block. Experimental results from these two different sets of experiments, 142 however, show that frontal wedge propagation ceases once the decollement 143 propagation reaches the high frictional patch / edge of the rigid acrylic sheet (see 144 electronic supplementary Fig. S1). This finding suggests that the use of high frictional 
145 patch on the basal glass plate is a suitable analog for simulating natural horst-block.

146 The advantage of using sandpaper over rigid block is that the hinterland buttress can

147 override the high frictional patch without limiting the amount of shortening during the

148 experimental run.

149 In the model setup, Zone I represents a graben in the seismogenic plate interface

150 and Zone II corresponds to a horst block in the subducting plate (Fig. 2). Although a

151 majority of our experiments were carried out with one high frictional patch between

152 zones of relatively lower friction on the basal fault, a few experiments were carried

153 out with two zones of high frictional patches to understand the effects of a series of

154 horst-and-graben structures. Experimental models were prepared by sieving sand

155 layers from a constant height of $20 \mathrm{~cm}$ in a rectangular glass-walled sandbox

156 apparatus over a rigid base of varying basal friction $\left(\mu_{b}\right)$ (Fig. 2). The length and

157 width of the apparatus are $110 \mathrm{~cm}$ and $35 \mathrm{~cm}$ respectively. The model width was more

158 than fifteen times its thickness to avoid the effects of friction at the interface of sand

159 layers and the glass sidewalls (Souloumiac et al., 2012). The coefficients of basal

160 friction $\left(\mu_{b}\right)$ were calculated separately from sliding experiments using dry non-

161 cohesive sand. Note that the values of $\mu_{b}$ used in our experiments are merely imposed

162 qualitatively for simulating natural situation that do not claim the exact values for

163 natural analogue. The glass walls of the sandbox were cleaned and dried carefully to

164 remove surface moisture. This process is important in order to prevent sticking of

165 sand to the glass walls. Experiments were carried out in controlled laboratory

166 conditions to avoid the influence of atmospheric moisture contents.

167 We used dry, non-cohesive natural quartz-rich (>90\%) sand, texturally matured

168 with well rounded grains (average sphericity of 0.8 ), as analogue material for scaled

169 model experiments simulating crustal scale brittle deformation (Davis et al., 1983; 
171 had a bulk density of $1600 \mathrm{~kg} / \mathrm{m}^{3}$, and a coefficient of internal friction close to 0.57 .

172 Our model scales to nature with a ratio of $2.7 \times 10^{-5}$, where $1 \mathrm{~cm}$ in the model is

173 equivalent to $360 \mathrm{~m}$ in nature (Table 1). The cohesion of model material (dry quartz

174 sand) in our experiment is around $20 \mathrm{~Pa}$, which scales to $2 \mathrm{MPa}$ (Gutscher et al.,

175 1998) for unconsolidated marine sediments (Hoshino et al., 1972). The models were

176 deformed in a pure shear box at a uniform velocity of $5 \mathrm{~mm} /$ minute using a

177 computer controlled step-up motor by setting a backstop at the rear of the sand layers.

178 Previous studies revealed that buttress geometry is important in the development of

179 wedge geometry in sand layers (Byrne et al., 1988; Persson and Sokoutis, 2002).

180 However, we used planar vertical buttress in our experimental setup in order to model

181 a mono-vergent accretionary wedge observed in the Japan Trench (Mulugeta, 1988;

182 Storti and McClay, 1995; Gutscher et al., 1998; Bose et al., 2009). Although sand

183 layer of $1 \mathrm{~cm}$ thickness should have been used in our experiments according to the

184 scaling law, we have exaggerated the thickness of sand layers to $2 \mathrm{~cm}$ in all

185 experiments for obtaining better resolution of deformation structures as well as to

186 understand the deformation mechanism clearly during the experimental run. However,

187 we ran experiments with sand layers of $1 \mathrm{~cm}$ thickness to verify the influence of

188 model thickness in experimental results. These experiments show broad resemblance

189 in the first order geometry of the wedge (see electronic supplementary Fig. S2) and

190 therefore validates the use of $2 \mathrm{~cm}$ thick sandlayers in the model experiments. During

191 the experimental run, we photographed through the lateral glass wall continuously

192 after an interval of 5 seconds, keeping the camera at a fixed distance from the model.

193 Model deformations were analyzed from successive photographs taken during the

194 experimental run. 


\section{Experimental Results}

Our experiments suggest that the frontal wedge near the Japan Trench has

evolved over varying down-dip frictional condition on the decollement during

subduction of horst-and-graben. In our experiments, the wedge started to grow above

Zone I by in-sequence thrusting at the initial stage and developed a gentle surface

201 slope $(\alpha)$ at uniform shortening rate (Figs. 3b-3c, 4a). The vertical growth of the

202 wedge at the backstop attained an almost stationary value when the model was

203 shortened by $5 \mathrm{~cm}$ in all experiments (Fig. 4b). At this stage, the frontal propagation

204 of the wedge dominated over the vertical growth through sequential thrusting until the

205 deformation front reached Zone II. During this stage the wedge developed a critical

206 taper, $\alpha$ equals $7.5^{\circ}$ (Figs. 3d, 4a), which is closer to the theoretical value of surface

207 slope $(\alpha)$ of $6^{\circ}$ obtained from "equation 1 " for $\beta=0, \mu_{b}=0.36$ and $\phi_{c}=0.57$.

208 However, the overestimation of $\alpha$ in the experimental result is self-consistent.

209 The mode of internal deformation and its geometry changed completely when

210 the decollement propagation reached the edge of high frictional patch (Zone II, $\mu_{b}=$

211 0.42), simulating a horst (Fig. 3e, see electronic supplementary Figs. S1 A [d] and B

$212[\mathrm{~d}])$. At this stage, decollement propagation ceased and the wedge formed over Zone I

213 started deforming internally by increasing the wedge height consistently, developing a

214 steep topographic slope (Fig. 4). This stage of wedge growth has been defined as

215 intermediate stage (Figs. 3e-3f). The topographic slope of the wedge at this stage

216 became much higher than the predicted value from "equation 1", leading the wedge to

217 grow to a super critical state. It is likely that the cessation of decollement propagation

218 promotes the development of supercritical wedge in order to accommodate the

219 amount of horizontal shortening, and eventually facilitates slope failure (Fig. 3f). 
220 During this stage experimental models demonstrated mechanical rotation and

221 reorientation of already deformed sand layers in the hanging wall, giving rise to a

222 complex deformation structures within the deforming wedge.

With further horizontal shortening, the deformation front crossed the Zone II

224 and propagated onto the region above zone I over low $\mu_{b}$, simulating another graben,

225 by the process of in-sequence thrusting and eventually, developed a separate wedge

226 with a low angle of taper as expected to occur over low basal friction. Such spatial

227 and temporal variations in the style and intensity of deformation across the wedge

228 finally gave rise to distinct topographic slope-break in the wedge geometry separating

229 the steep inner wedge from the low tapered outer wedge (Figs. 3g-3h and 4a). During

230 the growth of outer wedge, the internal deformation in the inner wedge completely

231 stopped (Fig. 4b) and the horizontal shortening was entirely accommodated by in-

232 sequence thrusting over weak fictional base. For simplicity in description, we describe

233 this stage of wedge growth as final stage, which characterizes the development of

234 topographic slope-break with the cessation of internal deformation within the inner

235 wedge. Experiments with varying width of Zone II showed that increasing the width

236 of the Zone II (e.g. $30 \mathrm{~cm}$ ) required large amount of shortening for the development

237 of the topographic slope-break (Figs. 5 and 4, see electronic supplementary Fig. S3).

238 The development of slope-break in the wedge geometry thus can be treated as a

239 potential indicator for interpreting long term frictional condition on the decollement.

240 Experiments with more than one high frictional patch (Zone II) on the basal

241 fault showed that the surface slope of outer wedge (e.g., the wedge over low $\mu_{b}$ ) was

242 increasing progressively with ongoing shortening once the decollement propagation

243 was again resisted by another high frictional patch in the front. As a consequence, the

244 wedge geometry was completely modified along with the destruction of topographic 
245 slope-break (Fig. 6h). With further shortening the outer wedge progressively merged

246 with the inner wedge, giving rise to a single wedge with steep uniform surface slope

247 (Fig. 6i). During this process of wedge modification, the inactive inner wedge again

248 resumed to deform by mechanically rotating all preexisting structures and thereby,

249 increasing the complexity of deformation structures towards the hinterland part of the

250 wedge (Fig. 6i, 6k). With continuous shortening, the deformation within this steep

251 wedge completely stopped once the deformation front propagated over another low

252 frictional base in the front with the onset of the development of new outer wedge by

253 in-sequence thrusting (Figs. 6j, 6k). Based on above results, it is evident that the

254 geometry of the frontal wedge is essentially transient with varying down-dip frictional

255 strength on the decollement in tectonically active convergent belts over long time 256 scale.

\section{Discussion}

\subsection{Implication of varying down-dip basal friction}

On the basis of the above observations and interpretations on the experimental

261 results we discuss below the role of basal friction in the structural development of

262 frontal wedge near the Japan Trench. Our study reveals that varying down-dip

263 frictional strength on the decollement causes a drastic change in the wedge taper,

264 giving rise to a steep inner wedge and gentle outer wedge. This lateral change in the

265 surface slope across the wedge separates the entire wedge into two distinctive

266 structural domains: (i) complex internal deformation within the inner wedge and (ii)

267 the outer wedge is deformed mostly by sequential thrusting. Experimental results

268 show that the growth of the inner wedge begins by in-sequence thrusting over low

269 frictional base following the model of critical angle of taper (Davis et al., 1983; 
Mulugeta, 1988; Koyi, 1995; Gutscher et al., 1998; Yamada et al., 2006; Bose et al.,

271 2009). However, with ongoing shortening the taper angle of the wedge progressively

272 steepens with the termination of decollement propagation by the increased frictional

273 resistance along the decollement. The steepening of the wedge slope couple with

274 intense internal deformation within it continues until the deformation front crosses

275 from the zone of high to low friction on the basal decollement. The progress of the

276 deformation front over the lower frictional base immediately stops internal

277 deformation within the deformed wedge (Figs. 3g- 3h) and thereby, initiates a

278 renewed phase of in-sequence thrusting in response to continuing horizontal

279 shortening, leading to the development of shallow taper outer wedge. This process of

280 wedge propagation over varying basal friction gives rise to the development of

281 topographic slope-break between the inner and the outer wedges. The characteristic

282 geometry of the slope-break in the tectonic wedge becomes prominent when the

283 wedge front continues to deform over a uniform low frictional base for large

284 horizontal shortening (Fig. 5a-g).

2854.2 Interpretation of wedge development near the Japan Trench

286 The present study has an important implication in understanding the

287 development of frontal wedge near the Japan Trench. Seismic sections across the

288 Japan Trench show that the slope of the frontal prism over horst-and-graben structure

289 changes from $10^{\circ}$ in the landward part to $4^{\circ}$ towards the trench (Fig. 1b). Comparing

290 our experimental results with seismic data from frontal wedge near the Japan Trench

291 suggest that the varying down-dip frictional strength along the basal decollement

292 caused the present geometry of the wedge and deformation structures within it near

293 the Japan Trench (Fig. 1b and 1c). Our experimental results suggest that the

294 subduction of horst-and-graben structure near the Japan Trench are potential factors 
295 for creating varying degree of coupling with the overriding plate that eventually

296 developed the characteristic topographic slope-break. It further reveals that the inner

297 wedge with steep slope over the horst block must have formed prior to the

298 propagation of deformation front over the graben sediments. Our experimental study

299 shows that initiation of growth of the outer wedge over low basal friction deactivates

300 the internal deformation of the inner wedge. This has led to infer that the present day

301 plate convergence near the Japan Trench is accommodating entirely by in-sequence

302 thrusting over the low friction graben sediments. Previous experimental findings

303 (Huiqi et al., 1992; Bose et al., 2009) along with the present study indicate that the

304 occurence of a series of imbricate thrusts over graben sediments, preserved in the

305 outer wedge of the Japan Trench (Kodaira et al., 2012; Nakamura et al., 2013), have

306 formed over relatively weak decollement (Figs. 7c).

307 The structural interpretations from the drill core samples collected during

308 JFAST and seismic data reveal that the frontal prism lying over the subducted horst

309 block ( high frictional patch) is structurally chaotic, which is also consistent with the

310 observed deformation structures in our experimental models. The dip of beds

311 measured in the core samples varies from $20^{\circ}$ to $80^{\circ}$ and they are also traversed by

312 numerous closely spaced core scale faults (Chester et al., 2013; Nakamura et al.,

313 2013; Kirkpatrick, 2014) (Fig. 7). Our experimental results show that the complexity

314 in the internal deformation within the inner wedge increases with the onset of

315 steepening of inner wedge slope when the frontal propagation of the decollement is

316 resisted by the high frictional patch during ongoing shortening (Figs. 3 and 4). This

317 has led to infer that the variably steeply dipping beds in the core samples might have

318 evolved through the process of mechanical rotation of earlier structures within the

319 hanging wall when the decollement propagation was either temporarily stopped or 
was very slow due to high-frictional resistance along the horst block. Based on above

321 discussions, it appears that subduction of horst-and-graben structure played a crucial

322 role in increasing the complexity of deformation structures observed at the drill site

323 near the Japan Trench. With continued plate convergence over time the deformation

324 front eventually crossed the high frictional patch resulting the break in the surface

325 slope observed between the inner and outer wedges in the frontal prism. In the

326 laboratory experiments, the break in the surface slope of the wedge becomes

327 prominent once the backstop overrides the high frictional patch and consequently,

328 develops outer wedge by in-sequence thrusting (Figs. 3g, 6f and 6j). Comparing our

329 experimental results with seismic images reveal that the buttress ( backstop in the

330 experimental setup) in the natural situation near the Japan Trench currently lies on the

331 west of the JFAST drilling site towards landward part of the wedge, as also predicted

332 by earlier workers (Tsuru et al., 2002) (Fig. 7b and 7c). Our experimental results

333 further reveal that the observed slope sediments between the inner and outer wedge in

334 the Japan Trench might have accumulated during the growth of supercritical wedge as

335 identified in the intermediate stage in experiments and the sediment accumulation

336 continued until the deformation front crossed the horst block (Fig. 3f). This, however,

337 does not rule out the possibility of rotational slumping of the slope sediments at the

338 frontal wedge by later reactivation during the 2011 megaearthquake event (Strasser et

339 al., 2013).

340 The present experimental study has also predicted why there is lack of natural

341 examples of the occurrence of multiple slope-breaks in accretionary prisms.

342 Experiments with two high frictional patches show that the cessation of the

343 propagation of outer wedge by another zone of high frictional patch in the front

344 modifies the wedge geometry thoroughly by mechanical rotation of all pre-existing 
345 deformation structures including the zone of topographic slope-break, forming a

346 wedge with a uniformly steep surface slope (Fig. 6). These observations have led to

347 infer that the subduction of the horst block in the Pacific plate lying currently on the

348 east of the Japan Trench will eventually modify the present wedge geometry having a

349 topographic slope -break to a uniformly steep slope.

\section{Conclusion:}

352

353

354

Our main conclusions are as follows:

1) Down-dip frictional variations on the decollement cause temporal and spatial variations in the geometry of the frontal wedge.

2) Surface slope-break develops when the deformation front crosses from high to low basal friction. The break in the surface slope separates the entire wedge into two distinct structural domains: inner and outer wedges.

3) The inner wedge is characterized by steep wedge slope and complex internal structures, whereas the outer wedge is deformed by in-sequence thrusting, leading to shallow taper angle.

4) The experimental models thoroughly explain the structural evolution of the frontal wedge near the Japan Trench observed in seismic images and borehole data.

5) We interpret that the complexity of internal deformation observed in core samples and localization of steep surface slope towards the landward part of the wedge near the Japan Trench is caused by the cessation of decollement propagation by the horst block in the subducting plate lying beneath JFAST drill site. 
6) The development of shallow taper outer wedge over the graben sediments by in-sequence thrusting marks the cessation of internal deformation in the rear part of the wedge ( inner wedge), creating the topographic slope-break near the Japan Trench.

Acknowledgement: We thank scientific and drilling staff on Drilling Vessel Chikyu for their constant assistance during the IODP expedition 343. We thank Ylona van

Dinther and Marc-Andre Gutscher for their insightful reviews and constructive

suggestions for improvement of this work. We also thank W.P. Schellart for his

guideline to revise the manuscript. The work is supported by MOES, Govt. of India and DST, Govt. of India grants to SB and PS acknowledge CSIR, India for financial support.

Bilek,S., 2007. Influence of Subducting Topography on Earthquake Rupture

Bose, S., Mandal,N., Mukhopadhyay,D.K., Mishra,P. 2009. An unstable

Boyer, S.E., Elliot, D., 1982.Thrustsystems. Am. Assoc. Pet. Geol.. 67,11961230.

Byrne, D.E., Davis D.M., Lynn, R.S., 1998.Loci and maximum size of thrust

Chapple, W.M., 1978.Mechanics of thin-skinned fold-and-thrust belts. Geol. Soc. Am. Bull.89,1189.

Chester, F.M., Rowe, C., Ujiie, K., Kirkpatrick, J., Regalla, C., Remitti, 

F.,Moore, J.C., Toy, V., Wolfson-Schwehr, M., Bose, S., Kameda, J., Mori, J.J., Brodsky, E.E., Eguchi, N., Toczko, S., Expedition 343 and 343T Scientists.Structure and composition of the plate-boundary slip zone for the 2011 Tohoku-Oki earthquake. Science 342, 1208-1211.

Dahlen,F.A., 1990. Critical Taper Model of Fold-and-Thrust Belts and Accretionary Wedges.Annu.Rev.EarthPlanet.Sci.18,55-99.

Das, S., Watts, A.B., 2009. Effects of subducting seafloor topography on the rupture characteristics of great subduction zone earthquakes. In:S. Lallemandand F. Funiciello(eds.), Subduction Zone Geodynamics, Springer-Verlag Berlin Heidelberg 103-118.

Davis, D.M., Suppe, J., Dahlen, F.A., 1983. Mechanics of fold-and-thrust belts and accretionary wedges. J. Geophys. Res. 88, 1153-1172.

Dominguez, S., Malavieille, J., Lallemand, S.E., 2000. Deformation of accretionary wedges in response to seamount subduction: Insights from sandbox experiments. Tectonics. 19, 182-196.

Groshong, R.H., 2006. 3-D Structural geology: a practical guide to quantitative surface and surface map interpretation. Springer, New York, p 400.

Gutscher, M. A., Kukowski, N., Malavieille, J., Lallemand, S., 1998. Material transfer in accretionary wedges from analysis of a systematic series of analog experiments. J. Struct. Geol. 20(4), 407-416.

Hoshino, K ., Koide, H., Inmni, K., lwamuraa, S., Mitsui, S., 1972. Mechanical properties of Japanese teritary sedimentary rocks under high confining pressures., Geol. Surv. of Jpn, Kawasaki, Japan, p 200.

Huiqi, L., McClay, K. R., Powell, D. 1992. Physical models of thrust wedges. In Thrust tectonics. Springer Netherlands, 71-81.

Kirkpatrick, J. D., Rowe, C. D., Ujiie, K., Moore, J. C., Regalla, C., Remitti, F., Toy, V., Wolfson-Schweh, M., Kameda, J., Bose, S., Chester, F. M., 2014. Structure and lithology of the Japan Trench subduction plate boundary fault. Tectonics. DOI: 10.1002/2014TC003695.

Kodaira, S., No, T., Nakamura, Y., Fujiwara, T., Kaiho, Y., Miura, S., Takahashi, N., Kaneda, Y., Taira, A., 2012. Coseismic fault rupture at the trench axis during the 2011 Tohoku-oki earthquake. Nat. Geosci. 5, 
433 Koyi, H., 1995. Mode of internal deformation of sand wedges. J. Struct. Geol.17, 293-300.

Lallemand, S. E., Schnürle, P., Malavieille, J., 1994. Coulomb theory applied to accretionary and nonaccretionary wedges: Possible causes for tectonic erosion and/or frontal accretion. J. Geophys. Res. 99, 12033-12055.

Lallemand, S. E., Malavieille, J., Calassou, S., 1992. Effects of oceanic ridge subduction on accretionary wedges: experimental modeling and marine observations. Tectonics, 11(6), 1301-1313.

Malavieille, J., 1984. Modelisation experimentale des chevauchements imbriques; application aux chaines de montagnes. Bull. Soc. Géol. Fr., (1), 129-138.

Mandal, N., Chattopadhyay, A., Bose S., 1997. Imbricate thrust spacing: experimental and theoretical analyses. In: Sengupta, S. (Ed.), Evolution of Geological Structures in Micro- to Macro-Scales. Chapman and Hall, London, 143 .

Mulugeta, G., 1988. Modeling the geometry of Coulomb thrust wedges. J. Struct.Geol.10, 847.

Nakamura, Y., Kodaira, S., Miura, S., Regalla, C., Takahashi,N., 2013. High resolution seismic imaging in the Japan Trench axis area of Miyagi, Northeastern Japan. Geophys. Res. Lett. 40, 1713-1718. doi:10.1002/grl.50364.

Pacheco,J.F.,Sykes,L.R.,Scholtz,C.H.,1993. Nature of seismic coupling along simple plateboundaries of the subduction type.J.Geophys.Res.98,1413314159.

Park, J. O., Tsuru, T., Kaneda, Y., Kono, Y., Kodaira, S., Takahashi, N., Kinoshita, H., 1999. A subducting seamount beneath the Nankai accretionary prism off Shikoku, southwestern Japan. Geophys. Res. Lett., 26(7), 931-934.

Persson, K.S., Sokoutis, D., 2002. Analogue models of orogenic wedges controlled byerosion. Tectonophysics. 356, 323 .

463 Schellart, W. P., 2000. Shear test results for cohesion and friction coefficients for 

different granular materials: scaling implications for their usage in analogue modelling. Tectonophysics. 324.1, 1-16.

Souloumiac, P., Mailot B., Leroy, Y.M., 2012. Bias due to side wall friction in sand box experiments, J. Struct. Geol., 35, 90 - 101.

Storti, F., McClay, K.R., 1995. Influence of syntectonic sedimentation thrust wedges in analogue models. Geology23, 999.

Strasser, M., Kölling, M., dos Santos Ferreira, C., Fink, H.G., Fujiwara, T., Henkel, S., Ikehara, K., Kanamatsu, T., Kawamura, K., Kodaira, S., Römer, M., Wefer, G., the R/V Sonne Cruise SO219A and JAMSTEC Cruise MR12-E01 scientists., 2013. A slump in the trench: Tracking the impact of the2011Tohoku- Okiearthquake.Geology.41,935-938.

Tanioka,Y., Ruff,L., Satake, K., 1997. What controls the lateral variation of large earthquake occurrence along the Japan Trench? IslandArc. 6,261-266.

Tsuru, T., Park, J. O., Miura, S., Kodaira, S., Kido, Y., Hayashi, T., 2002. Along - arc structural variation of the plate boundary at the Japan Trench margin: Implication of interplate coupling. J. Geophys. Res. 107(B12), ESE-11, 115.

von Huene, R., Culotta, R., 1989. Tectonic erosion at the front of the Japan Trench convergent margin. Tectonophysics. 160, 75-90.

von Huene, R., Lallemand, S., 1990.Tectonic erosion along the Japan and Peru convergent margins. Geol. Soc. Am. Bull. 102. 704-720.

von Huene, R., Ranero, C. R., Vannucchi, P., 2004. Generic model of subduction erosion. Geology. 32, 913-916.

vonHuene,R.,Klaeschen,D.,Fruehn,J., 1999.RelationbetweentheSubductingPlate andSeismicityAssociatedwiththeGreat1964AlaskaEarthquake.PureAppl. Geophys.154,575.

Wang, K., Hu, Y. (2006). Accretionary prisms in subduction earthquake cycles: The theory of dynamic Coulomb wedge, J. Geophys. Res. B06410, doi:10.1029/2005JB004094.

Yamada, Y., Baba, K., Matsuoka, T., 2006. Analogue and numerical modeling of accretionary prisms with a decollement in sediments. In: Buiter, S. J. H. \& Schreurs (eds) Analogue and numerical modeling of crustal- scale 
processes. Geol. Soc. London Spec. Pub, 253, 169-183.

497

498

499

500

501

502

503

504

505

506

507

508

509

510

511

512

513

514

515

516

\section{Figure Captions:}

Figure 1: (a) Location map, showing the eastern coastline of Honshu, bathymetry near Japan Trench and Tohoku earthquake epicenter (red star). The yellow arrow indicates the direction of plate convergence. Inset map shows location of Expedition 343 site C0019 (red star) along seismic section Line HD 33B (Fig.1b). Line HD 26B another seismic section line shown in figure 1c. (b) Image of seismic section Line HD 33B crossing the IODP drilling site C0019 with no vertical exaggeration. It shows change in topographic slope (marked red lines) from inner wedge $\left(\sim 10^{\circ}\right)$ to outer wedge $\left(\sim 4^{\circ}\right)$ (modified after Nakamura et al., 2013). (c) Image of seismic section Line 26B with V.E. 3, separated by $3.5 \mathrm{~km}$ from seismic line HD 33B. $\alpha_{i}$ and $\alpha_{o}$ are relative slopes of inner and outer wedges respectively, showing changes in topographic slope (modified after Nakamura et al., 2013). Pink line marks the decollement surface and blue arrow indicates the zone of topographic slope-break in both (b) and (c).

Figure 2: A sketch of the experimental setup showing 3D view of the model setup. Zones I and II represent low and high frictional contact zone respectively. Arrows on the right show the direction of shortening.

Figure 3: Progressive development of frontal wedge in sand models with $10 \mathrm{~cm}$ width of the Zone II. (a) Initial model, (b-e) Initial stage, (f) intermediate stage and (g-h) progressive development of wedge during the final stage (see text for details). Note that the deformation propagation towards front stopped after shortening of 14. $40 \mathrm{~cm}$, but hinterland elevation continued to increase (e). $18.10 \mathrm{~cm}$ shortening was accommodated within the wedge, reorienting earlier structures during intermediate 
stage (f). Further shortening moves the deformation front above the lower frictional base developing distinct slope-break (g-h).

Figure 4: Plots show different stages of wedge growth for varying width of zone II using high frictional patch (7 experiments) and rigid block (4 experiments). Wedge angle (a) and Wedge height at the backstop (b), are plotted as a function of actual displacement (horizontal shortening) in $\mathrm{cm}$. In the initial stage of the wedge growth, wedge angle (a) and wedge height (b) reached a constant value with horizontal displacement. The intermediate stage marks the sharp increase in both wedge angle (solid line) (a) and wedge height (solid line) (b). In the final stage wedge height attained a constant value (dash line) (b) with decreasing wedge slope (dash line) (a).

Figure 5: Final stage of wedge development for varying widths of high frictional patch: $2 \mathrm{~cm}(\mathrm{a}), 4 \mathrm{~cm}(\mathrm{~b}), 6 \mathrm{~cm}(\mathrm{c}), 10 \mathrm{~cm}(\mathrm{~d}), 12 \mathrm{~cm}(\mathrm{e}), 14 \mathrm{~cm}(\mathrm{f})$ and $30 \mathrm{~cm}(\mathrm{~g})$. The width of the model is $35 \mathrm{~cm}$ for all experiments. White arrow marks the zone of topographic slope-break between inner and outer wedge.

Figure 6: Progressive development of frontal wedge growth over multiple high frictional patch, forming alternate uniform slope and topographic slope-break. (a-d) Initial stage, (e) intermediate stage with steep uniform slope, (f-g) final stage showing the development of slope-break, (h) the process of destruction of outer wedge observed in figure (g) due to another high frictional in the front, leading to steep uniform surface slope (i), (j) development of new slope-break in the wedge geometry low basal friction, (k) Plots show the variations of wedge angle (purple) and wedge elevation at the hinterland buttress (green) as a function of horizontal displacement. Note that the combination of low tapered wedge at constant wedge elevation implies growing of wedge over low frictional base (yellow shade).

Figure 7: Compilation of core data with depth at IODP sites C0019 and comparison 
547 with experimental model. (a) Deformation unit in the core data shows variations in

548 bedding dip with depth and three structural domains are identified. (i) upper frontal

549 prism (0-275 mbsf) shows gently inclined bedding, (ii) lower frontal prism (276-820

550 mbsf) showing variable and steeply dipping beds characterized by folded and faulted

551 sediments, (iii) base section ( 820 mbsf to base of the hole) with shallow to horizontal

552 bedding represents in the footwall block in the subduction zone (modified after

553 Chester et al., 2013). (b) Experimental model shows resemblance in the changes of

554 bedding orientations with depth. Green arrows show the region in the experimental

555 model comparable with core data set. White dash line in the model replicates the

556 drilling site C0019 shown in Fig. 7c. (c) Details and interpretations of seismic image

557 along section HD 33B.Vertical Exaggeration = 2:1 (Modified after Kodaira et al.,

558 2012). Note that experimental model closely reproduces geometrical and structural

559 features observed in seismic image. Both experimental and seismic section show that

560 surface slope of the inner wedge is steeper than that of the outer wedge. Imbricate

561 thrusts are prominent within the outer wedge. The blue arrow marks the zone of

562 topographic slope-break between inner and outer wedges in Figs. 7b and 7c. 
Table 1

Modeling Parameters and material properties

\begin{tabular}{|c|c|c|c|}
\hline $\begin{array}{l}\text { Parameter and model } \\
\text { properties }\end{array}$ & $\begin{array}{l}\text { Sand } \\
\text { (analogue } \\
\text { model) }\end{array}$ & $\begin{array}{l}\text { Natural } \\
\text { ptototypes }\end{array}$ & $\begin{array}{l}\text { Ratio: } \\
\text { model/nature }\end{array}$ \\
\hline Length, L (m) & 0.01 & 360 & $\lambda=2.7 \times 10^{-5}$ \\
\hline Density $\left(\mathrm{kg} \mathrm{m}^{-3}\right)$ & 1600 & 2700 & $\delta=0.59$ \\
\hline $\begin{array}{l}\text { Internal friction angle, } \phi \\
\left({ }^{\circ}\right)\end{array}$ & $\sim 30$ & $30-40$ & $1-0.75$ \\
\hline Cohesion $(\mathrm{Pa})$ & 20 & $2 \times 10^{6}$ & $1 \times 10^{-5}$ \\
\hline Gravity, $\mathrm{g}\left(\mathrm{m} \mathrm{s}^{-2}\right)$ & 9.8 & 9.8 & $\gamma_{\mathrm{g}}=1$ \\
\hline $\begin{array}{l}\text { Deviatoric Stress } \\
(\sigma=\delta \cdot g . \mathrm{L})\end{array}$ & $157 \mathrm{~Pa}$ & $9.5 .10^{6}$ & $16.5 \times 10^{-6}$ \\
\hline
\end{tabular}




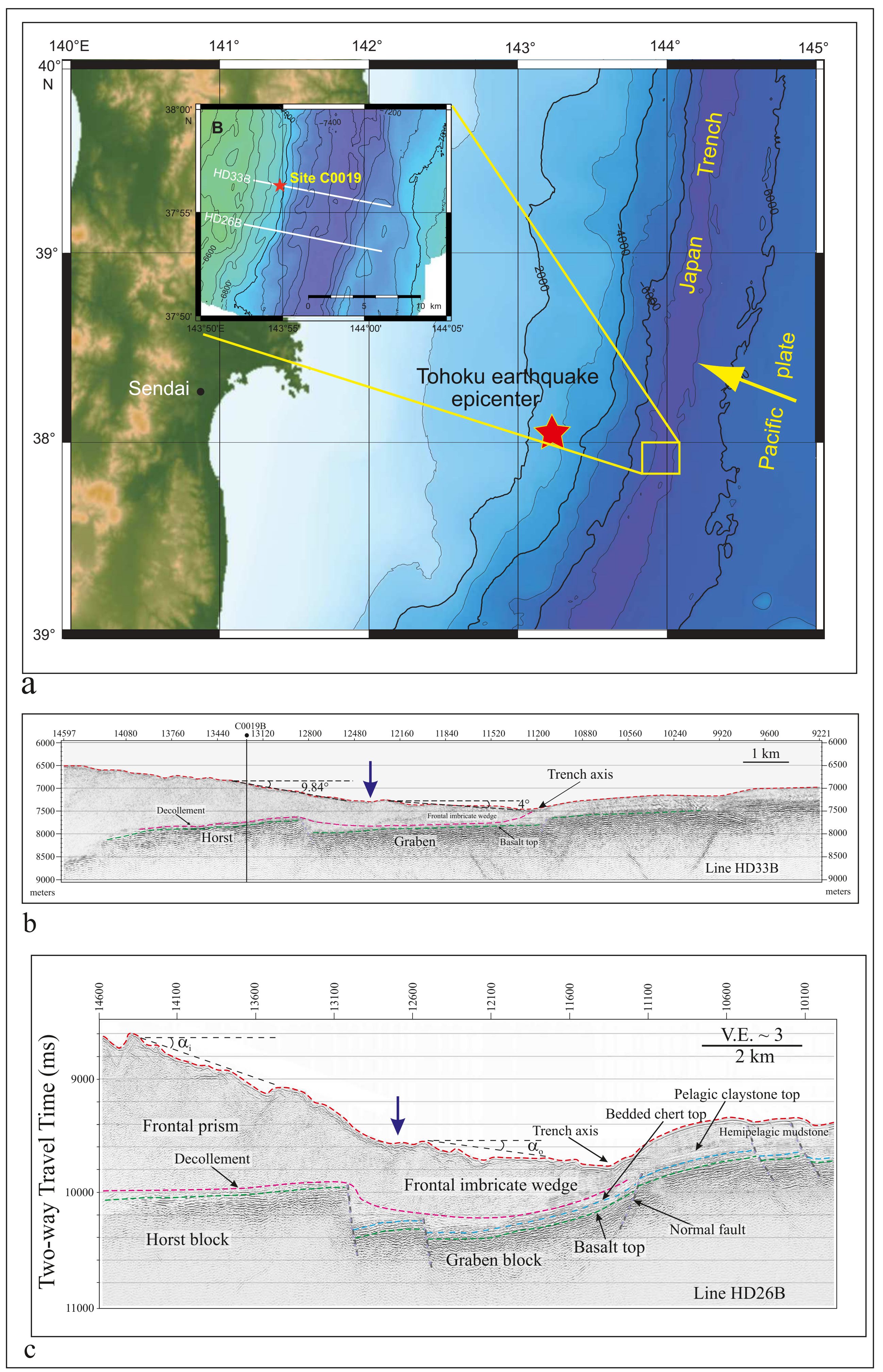




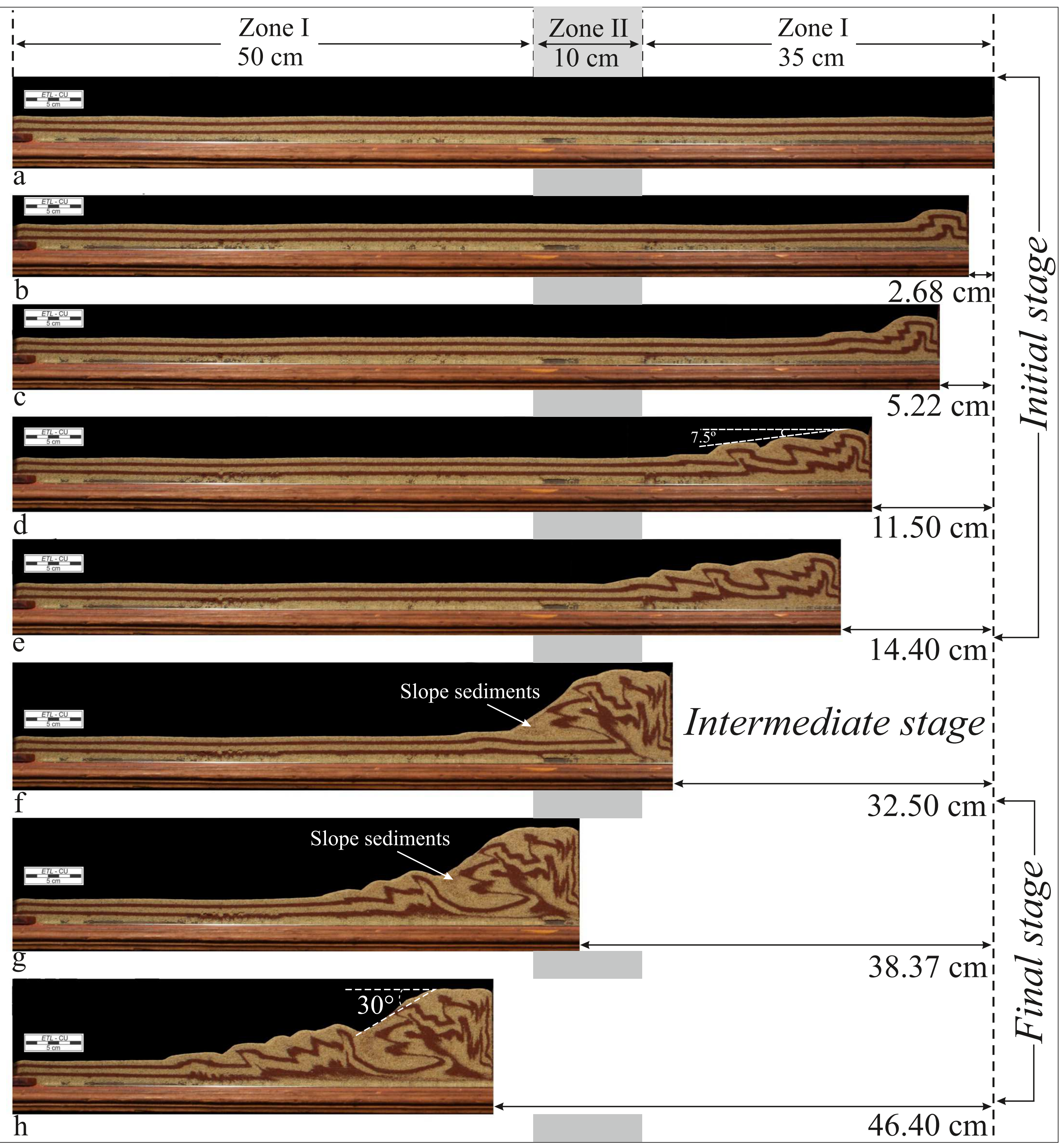




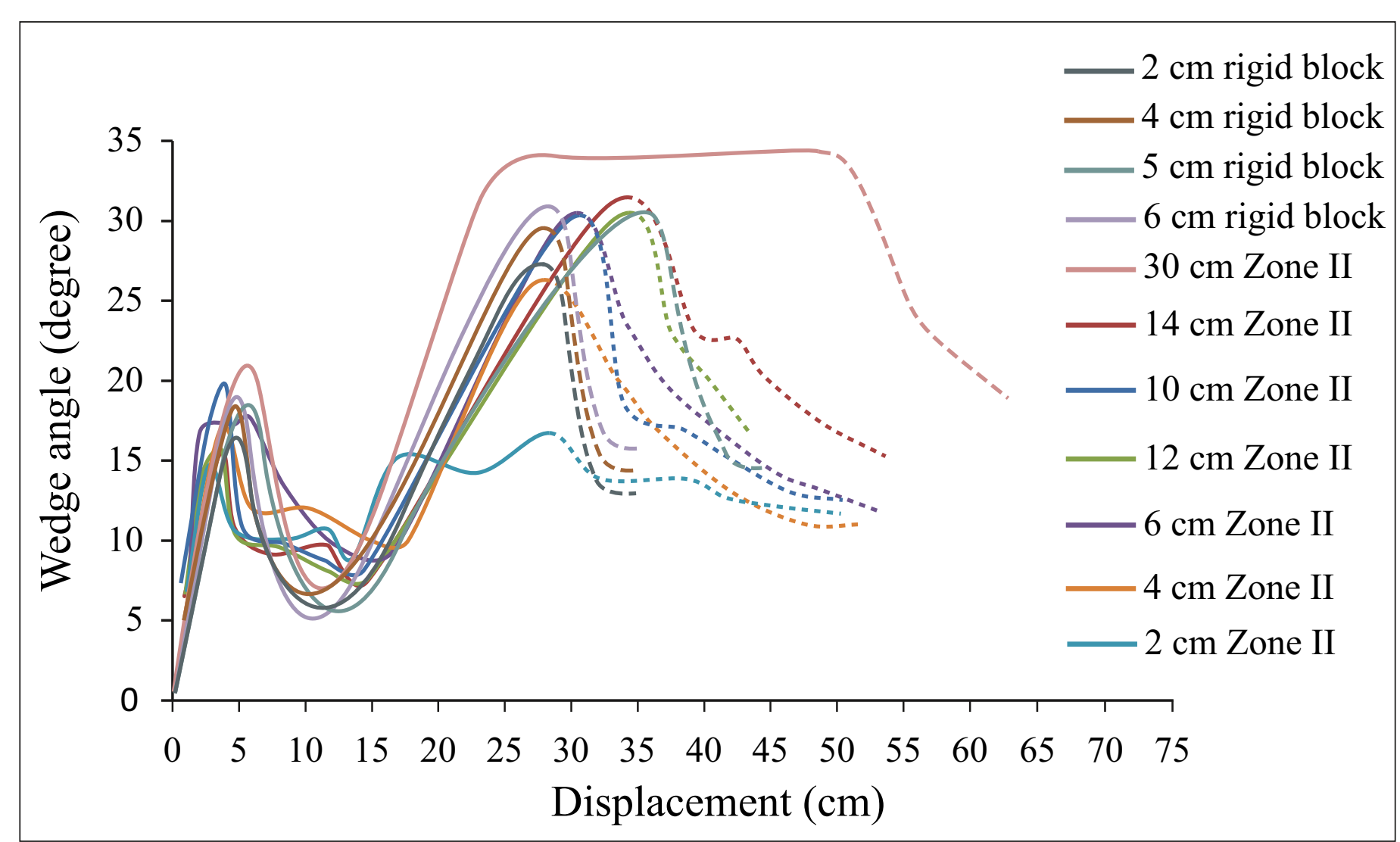

$\mathrm{a}$

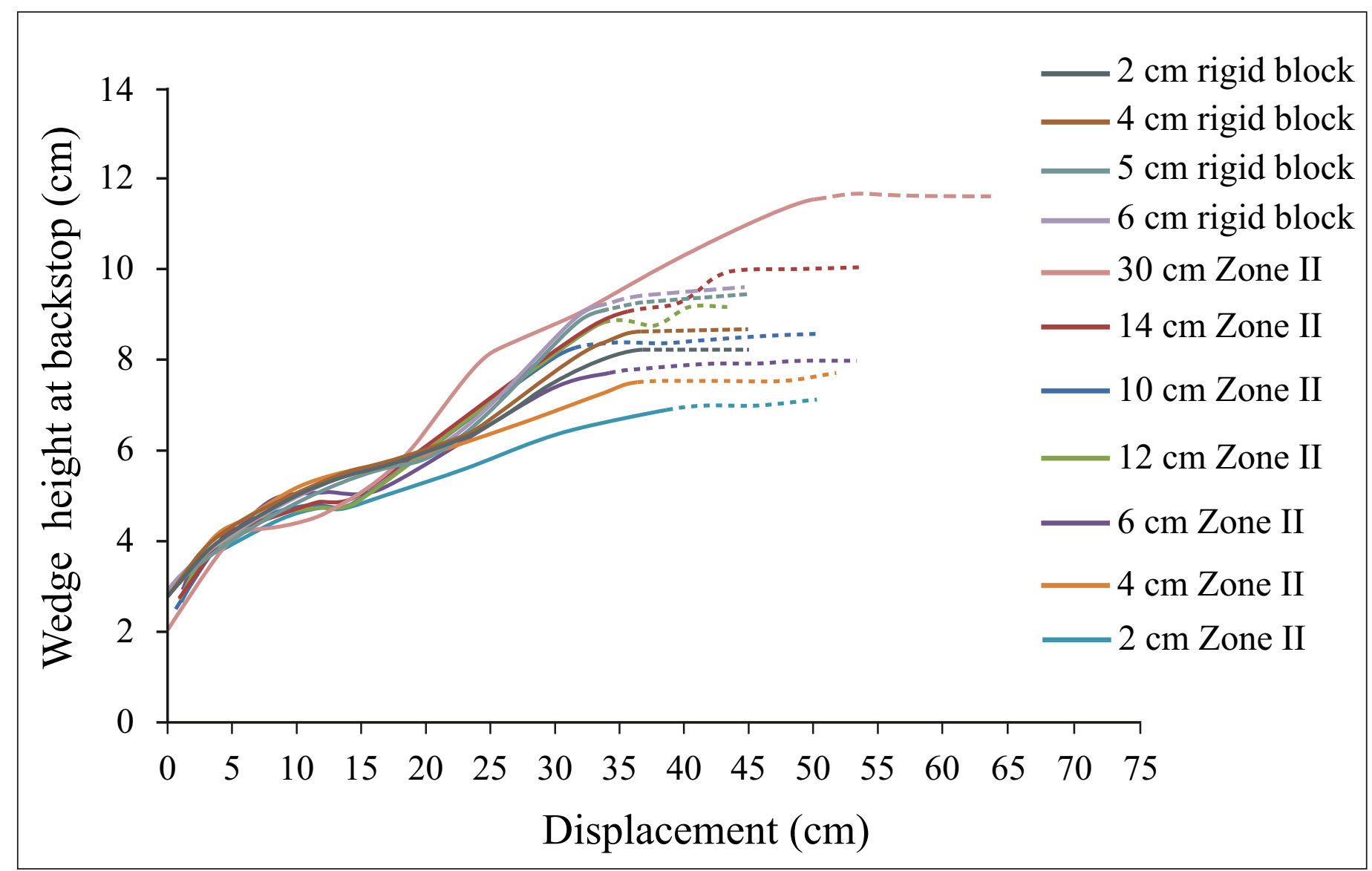

b 


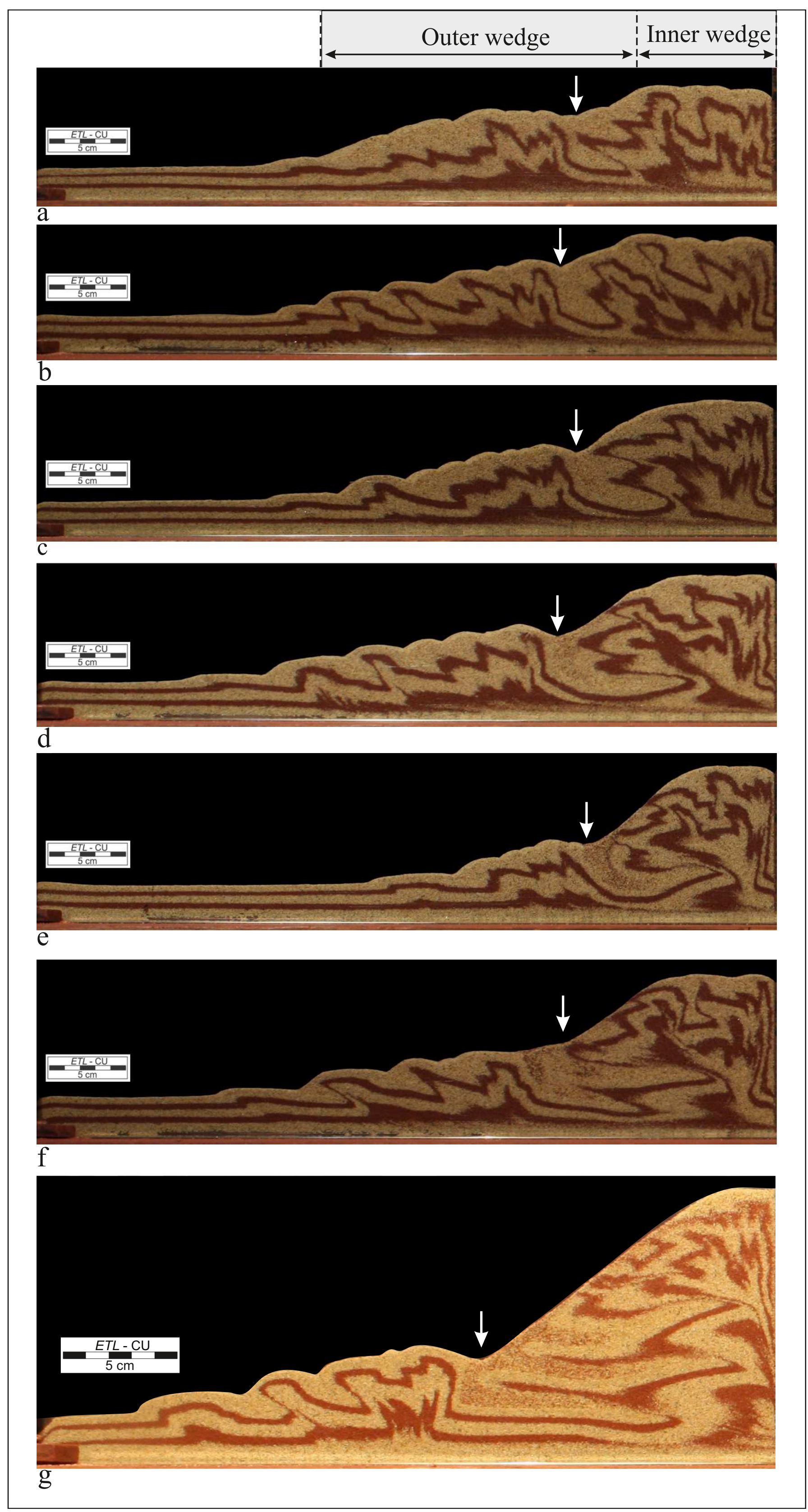




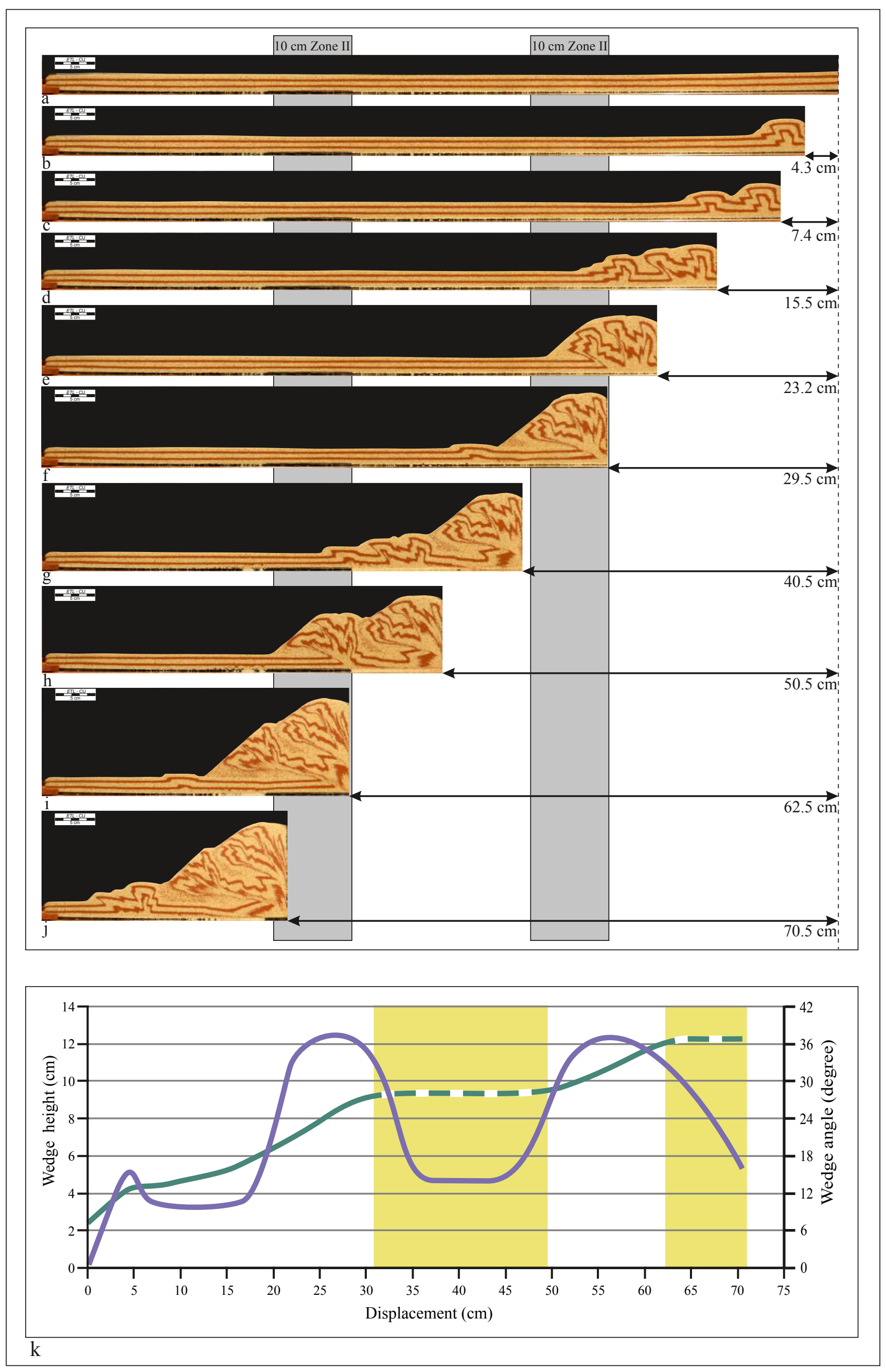


